\title{
REPRESENTAÇÕES DA TEMÁTICA DA MIGRAÇÃO NAS LITERATURAS ALEMÃ E ESPANHOLA DO SÉCULO XXI
}

\author{
Gabriela Gomes de Oliveira ${ }^{1}$ \\ Volker Jaeckel ${ }^{2}$
}

\begin{abstract}
Resumo: As literaturas de línguas alemã e espanhola do século XXI possuem traços significativos da diversidade cultural e intelectual proporcionada pelos processos migratórios. Desde as grandes ondas migratórias que se sucederam nos séculos XIX e XX, a produção literária desses dois países tem se tornado cada vez mais intercultural. Embora as trajetórias de migração tenham acontecido de forma distinta em cada país, é notório que a chegada de novos escritores migrantes refletiu de maneira muito positiva tanto na literatura alemã quanto na espanhola. Sob essa perspectiva, pretende-se analisar o panorama da migração dos dois locais e seu reflexo na produção literária dos mesmos. Para isso, teremos como base literária o romance em língua alemã Ohrfeige (2016) do escritor Abbas Khider, e as obras em espanhol El metro (2007) de Donato N’Dongo e No me cuentes tu vida (2012) de Luis García Montero.
\end{abstract}

Palavras-chave: Literatura Alemã; Literatura Espanhola; Migração.

\begin{abstract}
The German and Spanish language literature of the 21st century has significant traces of the cultural and intellectual diversity provided by migration processes. Since the great migration waves that followed in the 19th and 20th centuries, the literary production of these two countries has become increasingly intercultural. Although migration has taken place differently in each country, it is clear that the arrival of new migrant writers has had a very positive impact on both German and Spanish literature. From this perspective, the aim is to analyse the migration landscape of the two countries and its impact on their literary output. The literary base for this will be the German-language novel Ohrfeige (2016) by Abbas Khider and the Spanish-language works El metro (2007) by Donato N'Dongo and No me cuentes tu vida (2012) by Luis García Montero.
\end{abstract}

Keywords: German Literature; Spanish Literature; Migration.

1 Doutoranda em Estudos Literários pela Universidade de Colônia, Alemanha. Bolsista DAAD (Deutscher Akademischer Austauschdienst).

2 Professor Associado da Faculdade de Letras da Universidade Federal de Minas Gerais (UFMG) e docente permanente da Pós-Graduação em Letras da Universidade do Estado da Bahia (UNEB). 


\section{INTRODUÇÃO}

As literaturas de línguas alemã e espanhola produzidas por autores migrantes possuem trajetos distintos ao longo dos anos. Durante o século XIX, havia uma longa tradição de emigração para o Novo Mundo de pessoas que viviam sem liberdade, sem propriedades de terra e em condições muito precárias em seu país de origem. A população alemã que vivia sob essas terríveis circunstâncias emigrou, principalmente, para países como Estados Unidos, Argentina e Brasil - como se pode verificar muito bem no filme Die andere Heimat (2013) (“A outra terra natal”), do diretor alemão Edgar Reitz. Observa-se que, somente em 1854, cerca de 240.000 pessoas emigraram da Alemanha para fugir da miséria. No Novo Mundo, elas iniciaram uma vida nova, cultivavam a terra, fundaram vilarejos e marcaram o país anfitrião com aspectos de sua cultura de origem. No Brasil, por exemplo, pode-se perceber, ainda hoje, várias expressões culturais oriundas da Alemanha em diversas regiões do país, como em Santa Catarina, no Rio Grande do Sul, no Espírito Santo ou na Serra Fluminense. No caso da Espanha, o principal destino dos emigrantes foi a América Hispânica. Muitos espanhóis partiram para as colônias com o propósito de fazer fortuna, sendo que muitos deles alcançaram seu objetivo e retornaram à Espanha como pessoas ricas e com prestígio social. Esse acontecimento deu origem, na literatura de língua espanhola, à figura do 're-emigrante' retratada na obra Tormento (1884), do brilhante romancista do século XIX, Benito Pérez Galdós.

O século XX é marcado por duas grandes ondas de emigração que afetaram tanto a Alemanha quanto a Espanha. No primeiro caso, a emigração política se deu a partir de 1933 com a ascensão de Adolf Hitler e do nazismo ao poder, o que forçou a partida de milhares de alemães. Já no segundo caso, a emigração se deu por causa da ditadura de Francisco Franco depois de 1939, momento em que muitos espanhóis fugiram da repressão política e econômica do regime Franquista. Esses grandes movimentos migratórios que atingiram os dois países levaram muitos refugiados a emigrarem para a América Latina, sobretudo México e Argentina. Em menor número, também podemos destacar Brasil, Chile, Colômbia e outros países da América do Sul. Os fluxos migratórios saindo da Alemanha e Espanha se inverteram nas últimas décadas e, atualmente, são os dois países que mais acolhem refugiados e imigrantes de toda Europa. Obviamente, os percursos de migração que fizeram, e ainda fazem, parte das sociedades alemã e espanhola possuem um reflexo significativo na literatura produzida por esses países.

No cenário literário de língua alemã, muitos foram os autores imigrantes que escreveram sobre a nova vida a partir de seu olhar enquanto indivíduo que se encontra distante de sua terra natal. A escritora Marte Brill, por exemplo, nascida na cidade de Colônia, Alemanha, migrou para o Brasil em 1934 ao fugir do regime nacional-socialista de Adolf Hitler. No país, ela escreve a autobiografia Der Schmelztiegel ("O cadinho"), publicada postumamente em alemão no ano de 2003. No contexto atual, em que tanto Alemanha quanto Espanha se tornaram países de destino para milhares de imigrantes, autores de diferentes origens trazem uma nova face à literatura produzida em alemão e espanhol. Ao escrever sobre migração, cada autor possui um olhar distinto sobre essa temática, o que contribui de maneira relevante para a diversidade literária dos dois países. Sob essa perspectiva, ana- 
lisaremos, a seguir, aspectos do cenário migratório e da integração presentes no romance Ohrfeige ("Bofetada") de 2016, escrito em alemão pelo escritor iraquiano Abbas Khider. Ademais, nos debruçaremos sobre a leitura e compreensão da obra El metro, de 2007, do escritor Donato N’Dongo, exilado da Guiné Equatorial que vive na Espanha, e sobre o romance No me cuentes tu vida, publicado por Luis García Montero, em 2012.

\section{PANORAMA DA TEMÁTICA DA MIGRAÇÃO NA LITERATURA ALEMÃ CONTEMPORÂNEA}

A literatura de língua alemã possui traços significativos de um fazer literário multi- e intercultural, produzido por escritores e escritoras de diferentes origens. A partir de meados da década de 1950, as obras literárias escritas em alemão ganham novas faces e contornos, principalmente com a chegada de 'trabalhadores convidados', isto é, pessoas vindas de países como Turquia, Itália e Grécia que chegaram à Alemanha com o objetivo de auxiliar na reconstrução do país destruído pela Segunda Guerra Mundial. Os chamados Gastarbeiter vinham de pequenas vilas e eram pobres, além de não possuírem família na Alemanha. Em sua grande maioria, esses trabalhadores enviavam dinheiro a seus familiares que permaneceram no país de origem e, ao chegarem na Alemanha, não tinham conhecimentos do idioma. A primeira geração de Gastarbeiter constituiu família no país anfitrião e, muitos deles, trouxeram suas esposas e filhos depois de algum tempo em solo alemão. Seus filhos, que logo ingressaram em escolas alemãs, aprendiam o idioma e se integravam à sociedade, constituindo, portanto, a segunda geração. Todos esses fatores impulsionaram uma nova onda na literatura alemã, que passou a ser escrita por autores e autoras que possuíam histórico de migração no seio familiar.

Na maioria das vezes, os escritores que faziam parte da chamada Gastarbeiterliteratur (Literatura de trabalhadores convidados), cujo grande ápice literário se deu nas décadas de 1970 e 1980, escreviam sobre sua infância, sua casa ou conflitos de identidade. Embora carregue traços de sua identidade cultural e linguística em suas publicações, esse grupo de autores, jornalistas e poetas escolheram o alemão como idioma de sua escrita literária, como é o caso do italiano Franco Biondi, do sírio-alemão Rafik Schami e do libanês-alemão Jusuf Naoum, considerados precursores da Gastarbeiterliteratur. A segunda geração, por sua vez, ocupou, e ainda ocupa, espaços significativos na literatura produzida na Alemanha. Emine Sevgi Özdamar, filha de um trabalhador convidado, nasceu em 1946 em Malatya, na Turquia, e chegou à Alemanha em 1965 com sua família. Além de atriz, ela também escreve livros, em que conta a história de sua infância em Malatya, sua vida em Istambul e na Alemanha. Uma de suas publicações de maior sucesso foi Das Leben ist eine Karawanserei (A vida é uma caravana), de 1991.

O termo Gastarbeiterliteratur, embora tenha assumido um papel fundamental em estudos sobre a produção literária de autores não nascidos na Alemanha, é bastante controverso e até mesmo criticado pela recepção literária de língua alemã atualmente e tem sido pouco utilizado. Enquanto autores da 'Literatura de trabalhadores convidados', são incluídos à lista não apenas aqueles que possuem uma relação com o passado desses traba- 
lhadores, mas também outros autores que não se encaixam no histórico sociológico dessa terminologia. Segundo Pimonmas Photong-Wollmann, o termo 'trabalhador convidado' possui uma conotação negativa, uma vez que "[...] o conceito implica que os trabalhadores migrantes são indesejáveis a longo prazo" (1996, p. 34, tradução nossa) ${ }^{3}$. A autora acentua que as questões que envolvem a vida na Alemanha, as experiências no novo país e o passado dos 'trabalhadores convidados' não são mais parte dominante da literatura produzida por autores migrantes. Esses temas deram lugar a "novos problemas de convivência, [a]o estudo do intercâmbio pluralista-cultural e [a]os encontros culturais entre 'estrangeiros' e 'nativos"” (PHOTONG-WOLLMANN, 1996, p. 36, tradução nossa). ${ }^{4}$ Além disso, "os escritores 'estrangeiros' não são mais predominantemente os chamados 'trabalhadores convidados', eles são, sobretudo, intelectuais imigrantes, estudantes, emigrantes políticos e aqueles que vivem na Alemanha por razões pessoais" (PHOTONG-WOLLMANN, 1996, p. 36, tradução nossa). ${ }^{5}$

Em detrimento de Gastarbeiterliteratur recorre-se, em diversos estudos sobre o tema, ao conceito de Migrationsliteratur (Literatura de migração), que denota a literatura produzida como resultado da migração e cujo conteúdo é co-determinado pelo tema da migração. Desde os anos 2000, o termo inter-oder multikulturelle Literatur (Literatura inter- ou multicultural) também tem se tornado cada vez mais aceito. Diferentes estudiosos definem o pertencimento a uma ou outra categoria de maneiras diferentes, embora as nuances distintivas muitas vezes não sejam particularmente claras. Pode-se dizer que ambos os termos se referem mais a critérios de conteúdo do que ao contexto sociocultural e biográfico das obras. O termo "Literatura intercultural" enfatiza mais fortemente a filiação das obras a um discurso literário mais abrangente - que não se fixa na temática da migração. Em contraste, o termo "Literatura de migração", como visto acima, enfatiza o discurso sociocultural e o tema da migração. Em meio a esse debate terminológico denso e necessário surgem obras de grande expressão no cenário literário atual da Alemanha. Não se pretende aqui finalizar a discussão acerca do lugar ocupado por escritores estrangeiros ou alemães nas instâncias da literatura do país, antes, pretende-se abrir caminho para novos pensamentos tendo como ponto de partida a obra de Abbas Khider.

Assim como Khider, outros autores ocupam lugar de destaque no cenário da "Literatura de migração" e possuem um forte apreço do público leitor. Wladimir Kaminer, escritor nascido na antiga União Soviética, emigrou para Berlim em 1990 e iniciou na capital alemã seu percurso literário. Com mais de 26 obras literárias escritas em alemão, Kaminer é uma figura presente no meio midiático do país e dispõe de um significativo número de leitores. Dentre seus livros mais conhecidos, destacam-se Russendisko ("Balada russa"), de 2000, Schönhauser Allee ("Avenida Schönhauser"), de 2001, e Onkel Wanja kommt ("O tio Wanja está chegando"), de 2012. Sua mais recente publicação, Die Kreuzfahrer ("Os passageiros do

3 No original: “[...] wird begrifflich impliziert, daß die Arbeitsmigranten auf Dauer unerwünscht sind”.

4 No original: "neue Probleme des Zusammenlebens, die Auseinandersetzung mit dem pluralistisch kulturellen Austausch und die kulturelle Begegnung zwischen den 'Fremden' und den 'Einheimischen'“.

5 No original: “[...] die schreibenden 'Ausländer' sind nicht mehr vorwiegend die sogenannten 'Gastarbeiter', sie sind teilweise eingewanderte Intellektuelle, Studierende, politische Emigranten und diejenigen, die aus persönlichen Gründen in Deutschland leben“. 
cruzeiro marítimo”) de 2020, possui números significativos de vendas e ótimas avaliações nas livrarias da Alemanha. Outro autor de grande sucesso em meio à temática da migração é Feridun Zaimoglu. Nascido em Anatólia, Turquia, o escritor vive na Alemanha desde os seis meses de idade. Ele estudou arte e medicina na cidade de Kiel e escreve para jornais alemães como Die Welt, Frankfurter Rundschau, Die Zeit e FAZ. Zaimoglu foi condecorado diversas vezes por seu trabalho literário, como ocorreu em 2016 quando recebeu o Prêmio de Literatura de Berlim e a Cátedra Honorária do Estado de Schleswig-Holstein. Depois de Leyla, Liebesbrand ("Fogo ardente do amor") e Siebentürmeviertel ("Bairro das Sete Torres"”), sua mais recente publicação é o romance Die Geschichte der Frau ("A história da mulher"), de 2019.

\subsection{ABBAS KHIDER: OHRFEIGE (2016)}

O escritor Abbas Khider nasceu em Bagdá em 1973 e, no início dos anos 1990, chegou a ser preso onze vezes por se posicionar contrariamente ao regime de Saddam Hussein. Em 2000 ele encontra asilo na Alemanha, onde estudou literatura e filosofia em Munique e em Potsdam. No ano de 2007, Abbas Khider recebeu a cidadania alemã e, desde então, escreve romances que refletem os conflitos e as dificuldades enfrentadas por sua geração. Enquanto migrante, o autor procura narrar, de maneira ficcional, os diferentes caminhos e percalços que se formam diante daqueles que se encontram distantes de sua terra natal. Os personagens migrantes de origem árabe possuem uma forte presença nos textos de Khider, o que parece aproximá-lo de sua própria história. Além disso, ele considera temas como fuga, exílio e a destruição interna do indivíduo que viveu traumas relacionados com a experiência migratória como bastante significativos em seu fazer literário.

O romance Ohrfeige (Bofetada) foi publicado em 2016 em língua alemã, sendo este o quarto livro do autor. Ele retrata a situação de homens e mulheres de diferentes origens que migraram para a Alemanha no início dos anos 2000. Um dos temas centrais é a relação entre jovens iraquianos requerentes de asilo e os emaranhados da justiça e da burocracia alemã. As diversas narrativas internas, que contam a história de estrangeiros que buscam por uma chance de permanecer em solo alemão, se entrelaçam com a narrativa principal cujo foco se dá sobre o narrador Karim. Antes, porém, de adentrarmos o universo do romance torna-se necessário conhecer um pouco mais o contexto migratório que permeia a narrativa. Abbas Khider retrata a fuga de um iraquiano para a Europa e sua tentativa de conseguir asilo na Alemanha. Embora se trate de uma história ficcional, ela encontra reverberações no mundo real, uma vez que, de acordo com o Escritório Federal de Migração e Refugiados (Bundesamt für Migration und Flüchtlinge), somente no primeiro semestre de 2020, aproximadamente 22.000 pessoas apresentaram um pedido de asilo na Alemanha. ${ }^{6}$ Ainda de acordo com a plataforma, o asilo na Alemanha é um direito protegido pela Constituição. As pessoas que fogem da violência, da guerra e do terror podem encontrar proteção no país,

6 Disponível em: <https://www.bamf.de/SharedDocs/Anlagen/DE/Forschung/BerichtsreihenMigration

Integration/SoKo-Analysen/soko-halbjahresbericht-2020.html?nn=281840> Acesso em: 30 de novembro de 2020 . 
onde lhes são fornecidas informações sobre o procedimento e o direito de asilo, bem como sobre o contexto europeu. ${ }^{7}$

No que diz respeito ao contexto migratório descrito no romance analisado, um estudo realizado pelo pesquisador Menderes Candan (2017) e publicado pelo Centre for International Migration and Development apontou que, desde meados da década de 1950, a Alemanha tem sido um país de destino de migrantes iraquianos. Nos primeiros anos, o país recebeu inúmeros estudantes que ingressaram em universidades alemãs. Em grande parte, eles eram, principalmente, homens jovens pertencentes à elite iraquiana que recebiam bolsas de estudos de ambas as partes da Alemanha (Ocidental e Oriental), o que ocasionou um aumento exponencial do número de acadêmicos iraquianos no país. A maioria deles retornou para o Iraque ao completar seus estudos, mas, com a ascensão ao poder do Partido Baath ${ }^{8}$ , muitos estudantes que apoiavam os partidos políticos derrotados decidiram não voltar ao Iraque com medo de serem presos e solicitaram asilo político na Alemanha. O estudo ainda mostra que, desde a queda do regime Baath em 2003, aproximadamente 500 estudantes e pesquisadores convidados viajam todos os anos do Iraque para a Alemanha. Em 2016, aproximadamente 1.100 estudantes iraquianos foram matriculados em universidades alemãs (CANDAN, 2017, p. 8).

Outro contexto migratório apresentado por Menderes Candan (2017, p. 8-9) é o que abarca os refugiados do Iraque que, a partir da década de 1970, solicitaram asilo na Alemanha. O estudo mostra que, em princípio, sete razões podem ser identificadas como responsáveis por ondas de emigração do país: (1) as revoltas das etnias e religiões minoritárias em relação aos governos centrais em Bagdá, (2) as inúmeras tentativas de golpe de estado desde o início da década de 1930 até 1968, com a tomada de poder pelo Partido Baath, (3) a guerra entre o Irã e o Iraque de 1980 a 1988, (4) a invasão no Iraque em 1990 liderada pelos EUA, (5) o embargo econômico internacional contra o país a partir de 6 de agosto de 1990, (6) a guerra do Iraque em 2003 e as consequentes lutas internas entre grupos rivais e (7) o avanço da organização jihadista islâmica "Estado islâmico" desde o final de 2013.

Muitas vezes, os iraquianos fugiram primeiro para os países vizinhos como Irã, Turquia, Síria (até 2011) ou Jordânia. De lá, eles se dirigiram para a Europa Ocidental ou para a América do Norte, seja por intermédio de grupos de contrabando ilegal (às vezes com passaportes falsificados) ou com o apoio de organizações de ajuda internacional (por exemplo, o ACNUR). Na Europa Ocidental, a Alemanha foi um dos principais países-alvo dos refugiados iraquianos, juntamente com a Suécia e a Grã-Bretanha. Apenas em 2015, as autoridades alemãs receberam cerca de 96.000 solicitações de asilo de cidadãos iraquianos (CANDAN, 2017, p. 10).

É evidente que as ondas migratórias por que passou, e ainda passa, a Alemanha refletem no fazer intelectual, artístico e literário do país. Exemplo disso são as obras literárias

7 Disponível em: <https://www.bamf.de/DE/Themen/AsylFluechtlingsschutz/asylfluechtlingsschutz-node.html> Acesso em: 30 de novembro de 2020 .

8 O partido foi fundado em 1947 e defendia o Baathismo, que seria uma mistura ideológica de nacionalismo árabe, pan-arabismo, socialismo árabe e anti-imperialismo. O Baathismo pedia a unificação do mundo árabe em um único estado e mobilizou movimentos nacionalistas. Disponível em: $<$ https://historiaislamica.com.br/baathismo-conheca-a-historia-do-socialismo-arabe/> Acesso em: 30 de novembro de 2020. 
escritas em alemão por autores de origem árabe como o iraquiano Najem Wali, que possui 14 livros publicados, sendo o último de 2018 com o título Abraham trifft Ibrahîm. Streifzüge durch Bibel und Koran (Abraham conhece Ibrahîm. Ensaios através da Bíblia e do Alcorão). O iraniano-alemão Navid Kermani também desponta como um autor de sucesso, tendo publicado 24 livros e diversos artigos científicos sobre literatura. Sua mais recente publicação foi a coletânea Morgen ist da: Reden (Amanhã está aqui: Discursos), de 2019. Nesse contexto fértil de obras e autores migrantes que escolheram o idioma alemão como o suporte de seu fazer literário surge a figura do próprio Abbas Khider, cujo mais recente romance Ohrfeige (“Bofetada”), de 2016, será analisado a seguir.

O protagonista do romance é Karim Mensy, que partiu do Iraque clandestinamente rumo à França em 2001. Devido a um problema de percurso, o jovem, que atravessara quase toda a Europa escondido em um caminhão de carga, chega à Alemanha juntamente com outros viajantes e, impedido de se deslocar para Paris e encontrar seu tio, decide ficar em solo alemão e solicitar asilo político. A cena inicial da narrativa mostra o momento em que Karim mantém como refém uma funcionária do departamento de migração, Frau Schulz, e decide contar para ela sua trajetória até aquele momento. Ao se apresentar, o personagem acentua de forma crítica que o seu próprio nome, enquanto estrangeiro, soa difícil para os alemães e, por isso, se torna completamente indiferente para funcionários do serviço público do país. "Acho que para você eu era o requerente de asilo 3873 ou algo assim. Não mais do que os números que tive que escolher para esperar. Foi uma espera inútil, que só assumi porque tinha a esperança de ter uma chance" (KHIDER, 2916, p. 12, tradução nossa). ${ }^{9}$ A questão da longa espera por conseguir uma autorização de residência na Alemanha é algo de muita relevância na obra. Quando as autoridades alemãs descobrem que Karim está ilegalmente no país, ele é levado a uma delegacia de Munique, seu local de chegada, é interrogado, cadastrado no sistema da polícia de imigração e levado a um abrigo na cidade de Bayreuth.

O abrigo se situa nos arredores da cidade e o prédio serve de moradia para imigrantes que, assim como Karim, pretendem solicitar asilo na Alemanha e aguardam pelos procedimentos burocráticos. A área possui prédios idênticos compostos por escritórios do Serviço de Refugiados, estação policial, clínica médica e as moradias dos solicitantes de asilo. Havia um intenso controle de entrada e saída, além de revista das sacolas de compras, dos maços de cigarros e controle regular dos documentos de identificação. Cada um dos três andares do edifício era nomeado conforme a nacionalidade de seus moradores: "Havia a 'área albanesa', o 'canto africano', o 'espaço afegão' e a 'sala bielorrussa' (KHIDER, 2016, p. 60, tradução nossa). ${ }^{10}$ Além da presença de iraquianos, o abrigo também contava com albaneses, nepaleses, curdos, paquistaneses, bielorussos, iranianos, sírios, dentre outros. Durante sua estadia, os imigrantes não poderiam trabalhar, estudar ou viajar para fora da

9 No original: "Für Sie war ich wohl Asylant 3873 oder so. Nicht mehr wert als die Nummern, die ich ziehen musste, um zu warten. Es war ein sinnloses Warten, das ich nur auf mich genommen habe, weil ich die Hoffnung hatte, [...] eine Chance zu bekommen“.

10 No original: “Es gab das 'albanische Gebiet', das 'afrikanische Eck', den 'afghanischen Raum' und die 'weißrussische Stube". 
cidade, de modo que o tédio e a espera por uma resposta do governo os desestabilizavam emocionalmente.

Um tempo após sua chegada, Karim teria uma audiência com as autoridades do Departamento de Migração, onde ele lhes contaria o motivo pelo qual requer asilo político na Alemanha e a forma como ingressou no país. Embora o Iraque, no início dos anos 2000, ainda estivesse sob o regime de Saddam Hussein e o jovem iraquiano não apoiasse o governo, o fator político não foi determinante para sua emigração. Ele revela a Frau Schulz que, desde a adolescência, sofre com possíveis distúrbios hormonais que provocam um aumento de seus seios que, em decorrência disso, possuem traços femininos. Por vergonha de sua família e amigos e por medo do alistamento obrigatório no exército, Karim decide partir do Iraque com a ajuda financeira de seu pai, que não sabe do problema do filho. O protagonista esperava conseguir trabalho na Alemanha, de modo a financiar uma cirurgia de reparação e iniciar uma nova vida no país. "Cara Frau Schulz, deixei meu país natal porque sonho em me tornar um homem normal. Isso é tudo" (KHIDER, 2016, p. 93, tradução nossa). ${ }^{11} \mathrm{O}$ medo de seu segredo ser descoberto pelos demais moradores do abrigo atormenta Karim e, sabendo que esse motivo de saúde não seria suficiente para convencer as autoridades alemãs a lhe concederem asilo, ele decide mentir.

Ao Departamento de Migração ele conta que um professor da escola, extremamente nacionalista e seguidor de Saddam Hussein, sempre introduzia em suas aulas algumas falas e discursos do ditador. "No dia da entrega dos boletins, o professor Hylal nos disse que achava uma pena que, por exemplo, nas aulas de matemática não se tenha tido a oportunidade de analisar a sabedoria do presidente" (KHIDER, 2016, p. 108, tradução nossa). ${ }^{12}$ Foi então que Karim teria feito uma piada diante da classe envolvendo o ditador e sua esposa. Com a criação dessa história, ele afirma ter fugido do Iraque por medo de ser perseguido, torturado e morto pelo regime de Saddam, uma vez que o jovem haveria ridicularizado o governo. Enquanto aguarda ansiosamente pela resposta das autoridades alemães referente a seu pedido de asilo, o protagonista sonha com as coisas que faria quando o visto de permanência chegasse.

\begin{abstract}
Imaginei uma nova vida como um homem livre. Eu encontraria um cirurgião que me daria um peito liso, finalmente eu seria capaz de usar roupas justas e caminhar pelas ruas com a cabeça erguida. Eu conseguiria um lugar na universidade, uma linda colega da universidade como namorada, com a qual eu poderia me comunicar exclusivamente em alemão após um curto período de tempo. Logo eu também teria um emprego com um bom salário em uma empresa internacional, sentado em um arranha-céus feito de vidro e aço, e do meu escritório espaçoso eu poderia ver todos os telhados da cidade. Eu traria meus pais do Iraque para cá, compraria uma casa junto ao mar, e no verão iríamos todos juntos para lá, meu
\end{abstract}

11 No original: "Liebe Frau Schulz, ich habe meine Heimat verlassen, weil ich davon träume, ein normaler Mann zu werde. Das ist alles".

12 No original: „Am Tag der Zeugnisvergabe erzählte uns der Lehrer Hylal, er finde schade, dass man beispielsweise im Mathematikunterricht nicht die Möglichkeit habe, die Weisheiten des Präsidenten zu analysieren“. 
pai, minha mãe e meu grande amor da universidade. Nossos rostos ficariam tão felizes quanto os dos bichos de pelúcia (KHIDER, 2016, p. 116-117, tradução nossa). ${ }^{13}$

Os pensamentos e sonhos do protagonista são semelhantes aos de muitos imigrantes que procuram por uma nova chance, seja na Alemanha ou em outro país. A terrível sensação da espera pelo envelope contendo a resposta do governo alemão é um fato que sempre vem à tona no romance. Por não possuírem uma ocupação diária, os estrangeiros requerentes de asilo se sentem aflitos e desamparados, muitas vezes com medo de serem impedidos de ficar. Ao longo do romance, Karim narra a história de vida de vários de seus companheiros de abrigo e é possível notar que muitas dessas trajetórias se entrecruzam. A maioria deles foge de zonas de guerra, da pobreza e da perseguição política e têm um único grande objetivo: recomeçar a vida. Contudo, suas esperanças diminuem quando o resultado da solicitação de asilo não chega e Karim é transferido para outro abrigo na pequena cidade de Niederhofen. Após um tempo esperando por uma resposta e depois de vários contratempos, o protagonista é informado sobre o indeferimento de seu pedido. Muito atormentado e triste com a situação, ele decide retornar a Munique e relembra sua insatisfação ao compartilhá-la com Frau Schulz:

Foi isso, Sra. Schulz, foi o meu tempo na Alemanha. Vivi aqui três anos e quatro meses. [...] Muita coisa aconteceu durante este tempo, mas nada de que eu me orgulhe. Ainda não sou um homem normal, ainda tenho os malditos peitos. Sabe de uma coisa? Se eu tivesse começado a trabalhar ilegalmente mais cedo, provavelmente eu poderia ter financiado esta operação há muito tempo. Mas eu sou um idiota honesto. Tudo o que eu consegui foi um gigantesco nada. Ao invés da universidade, fui para o abrigo de sem-teto [...]. Ao invés de estudantes e professores, eu saí com criminosos, fanáticos e trapaceiros. E agora? Estou de volta onde comecei. Não pude ficar em Bagdá, não estou autorizado a ficar na Alemanha. Vamos ver o que acontece na Finlândia (KHIDER, 2016, p. 217-218, tradução nossa). ${ }^{14}$

\footnotetext{
13 No original: "Ich stellte mir ein neues Leben als freier Mensch vor. Ich würde einen Chirurgen finden, der mir eine flache Brust schenkte, würde endlich enge Kleidung tragen können und erhobenen Hauptes durch die Straßen gehen. Ich bekäme einen Platz an der Universität, eine hübsche Kommilitonin als Freundin, mit der ich mich nach kurzer Zeit schon ausschließlich auf Deutsch verständigen können. Bald hätte ich auch einen Job mit einem guten Gehalt bei einer internationalen Firma, die in einem Wolkenkratzer aus Glas und Stahl säße, und von meinem geräumigen Büro aus könnte ich alle Dächer der Stadt sehen. Ich würde meine Eltern aus dem Irak herholen, mir ein Haus am Meer kaufen, und im Sommer würden wir alle zusammen, mein Vater, meine Mutter und meine große Liebe von der Universität, dort Urlaub machen. Unsere Gesichter sähen so glücklich aus wie die von Kuscheltieren“.
}

14 No original: "Das war es, Frau Schulz, das war meine Zeit in Deutschland. Drei Jahre und vier Monate habe ich hier gelebt. [...] Es geschah viel in dieser Zeit, aber nichts, worauf ich stolz bin. Noch immer bin ich kein normaler Mann, noch immer habe ich die verdammten Brüste. Wissen Sie was? Hätte ich früher angefangen schwarzzuarbeiten, hätte ich die Operation vermutlich längst finanzieren können. Aber ich bin eben doch ein aufrichtiger Trottel. Alles, was ich erreicht habe, ist ein gigantisches Nichts. [...] Statt an der Universität war ich im Obdachlosenheim [...]. Statt mit Studenten und Professoren gab ich mit Kriminellen, Fanatikern und Strichern ab. Und jetzt? Ich stehe wieder ganz am Anfang. [...] In Bagdad konnte ich nicht bleiben, in Deutschland darf ich nicht bleiben. Mal gucken, was in Finnland passiert“. 
A decisão de tentar chegar até a Finlândia é a mesma que muitos outros imigrantes tiveram, ou ainda têm, que tomar. Com o pedido de asilo negado, todos os planos e expectativas que Karim tinham com relação ao futuro desapareceram. Depois de passar tanto tempo na Alemanha apenas esperando o resultado final dos trâmites do Departamento de Migração, o protagonista voltou ao ponto de partida. Embora o romance de Abbas Khider retrate a vida de um imigrante sob o ponto de vista ficcional, a história de Karim poderia ser a história de várias outras pessoas que se arriscam em travessias perigosas e ilegais para conseguirem uma nova chance em um país com melhores condições sociais e econômicas. As dificuldades enfrentadas por esses indivíduos durante o trajeto até o novo país e a espera quase interminável por uma resposta positiva do governo anfitrião são fatores que, possivelmente, provocam um enorme estresse emocional. Abbas Khider acentua esse aspecto ao longo de toda a obra, principalmente quando, ao final, Karim percebe que não manteve Frau Schulz como sua refém. Ele simplesmente sonhou que dialogava com a funcionária do Serviço de Migração justamente por se sentir injustiçado pelos agentes burocráticos da Alemanha.

\section{PANORAMA DA TEMÁTICA DA MIGRAÇÃO NA LITERATURA ESPANHOLA CONTEMPORÂNEA}

A Espanha é um dos países europeus que, junto com a República Federal da Alemanha, recebe mais migrantes. Porém, o tema das migrações não tem a mesma repercussão na literatura contemporânea espanhola como na Alemanha. São ainda poucos os autores espanhóis que publicam textos sobre essa temática. Depois das primeiras catástrofes acontecidas com imigrantes afogados no estreito de Gibraltar, ${ }^{15}$ a assim chamada patera ${ }^{16}$ virou um símbolo para esse tipo de migração. ${ }^{17}$ No outono de 2020, centenas de migrantes chegaram diariamente no litoral das Ilhas Canárias ou foram resgatados por botes salva-vidas ainda no mar. $^{18}$

Existe um grande número de romances e contos que tematiza essa travessia perigosa que, muitas vezes, termina com o afogamento dos refugiados que viajam nas pateras e nos

15 A primeiras mortes aconteceram num naufrágio em 1 de novembro de 1988. Até hoje são mais de 7000 mortes nas travessias perigosas à Espanha. Disponível em: <https://elpais.com/politica/2018/10/31/actualidad/1541019436_484192. html> Acesso em: 01 de dezembro de 2020.

16 Patera é originalmente um pequeno barco de madeira, sem convés, com fundo plano e pouco calado, usado para pescar ou caçar patos em águas rasas, termo aplicado às embarcações utilizadas por imigrantes ilegais para chegar da África à Europa.

17 Sobre a importância da patera no drama da imigração africana existem vários contos e uma pequena bibliografia, especialmente relevante é Zofko 2019, p. 19-43 que compilou essas informações no capítulo "La patera como símbolo de la inmigración".

18 Se calcula que, durante o ano 2020 até finais de novembro, chegaram 19.000 migrantes nas Ilhas Canárias, enquanto se afogaram outros 500 durante a travessia. Disponível em: <https://elpais.com/espana/2020-11-25/reencuentro-en-el-muelle-de-arguineguin.html> Acesso em: 01 de dezembro de 2020. 
cayucos. ${ }^{19}$ A fuga do continente africano pelo mar ganhou um lugar de destaque na literatura espanhola contemporânea, ao lado de outro topos muito presente: o da criminalidade que os africanos protagonizam ou sofrem como vítimas.

Em seu estudo intitulado Itinerários narrativos de la inmigración actual em España, a pesquisadora croata Maja Zovko analisa ou menciona 70 obras da literatura espanhola, publicadas durante os anos de 1993 e 2018. Entre elas, pode-se mencionar publicações de autores conhecidos como Los novios búlgaros de Eduardo Mendicutti (1993), Yo Mohamed. Historias de inmigrantes en un país de emigrantes (1995) de Rafael Torres, Un día, cuando pueda llevarte a Varsovia (1997) de Lorenzo Silva, Fátima de los naufragios (1998) de Lourdes Ortiz, Háblame musa, de aquel varón (1998) de Dulce Chacón, a coleção de contos Por la via de Tarifa (1999) de Nieves García Benito, Las voces del estrecho (2000) de Andrés Sorel, Gálvez en la frontera (2001) de Jorge Martínez Reverte, Al calor del día (2001) de Miguel Naveros e Ramito de hierbabuena (2001) de Gerardo Muñoz Llorente.

Como observou Marco Kunz, muitas dessas obras estão longe de serem produções literárias mestras que deixarão rastros na história da literatura. Porém, elas atendem a uma necessidade de informar aos leitores, por meio de um realismo antiquado e artisticamente insatisfatório, o que estava acontecendo no país naquele momento (KUNZ, 2002, p. 113). Dessa forma, houve uma mudança com relação à atenção dos leitores para o problema da imigração, justamente num momento em que a recuperação da memória histórica da ditadura e da guerra civil na Espanha estava ganhando força, depois de décadas de silenciamento forçado que evitava a discussão sobre os sofrimentos dos emigrantes republicanos que saíram em 1939 para o exílio a países da África, da Europa e das Américas.

\subsection{DONATO N'DONGO: EL METRO (2007)}

Donato N'Dongo é um exilado da Guiné Equatorial que vive na Espanha há mais de 25 anos. Ele é conhecido como ensaísta, escritor, jornalista e político que fez parte do governo Guinéu-Equatoriano do exílio na Espanha. Até o momento publicou três romances: Las tinieblas de tu memoria negra (1987), Los poderes de la tempestad (1997) e El metro (2007). Donato é, sem dúvida alguma, uma das vozes mais articuladas no campo literário do seu país de origem. Suas obras foram traduzidas ao inglês, francês, italiano e, muito recentemente, ao português do Brasil.

El metro é um romance em cujo centro está a personagem do jovem migrante africano Lambert Obama Ondo, que compartilha com o leitor as suas aventuras e peripécias no percurso do seu país de origem, Camarões, para a Espanha, uma trajetória trágica vivenciada por milhares de imigrantes e refugiados até a atualidade. El metro é um livro sobre as pessoas deslocadas que migram para os países estrangeiros (HERRERA, 2019, p. 99), geralmente situados no hemisfério norte da terra, em busca de bem-estar, estabilidade e segu-

19 Cayuco é uma barca grande utilizada para pesca artesanal na costa africana que leva o motor fora de bordo. É um termo utilizado na Guiné-Equatorial e nas Ilhas Canárias. Veja a reportagem sobre a chegada massiva de migrantes no Arquipélago das Ilhas canárias em novembro de 2020. Disponível em: <https://cadenaser.com/emisora/2020/11/07/ ser_las_palmas/1604749414_580849.html> Acesso em: 01 de dezembro de 2020. 
rança. N'dongo conta a crua realidade de Camarões, onde as crenças e tradições ancestrais impedem a felicidade de Obama com sua namorada. Primeiro, ele se muda de sua vila de Mbalmayo para a capital de Camarões, Yaoundé, e depois para a cidade portuária Douala. Isto ocorre, principalmente, devido a dois fatores: a morte de sua mãe Dorothée Oyana; e o fato de que teve de se afastar da sua amada Anne Mengue, perdendo assim os vínculos com a sua origem e também a sua estabilidade emocional. As frágeis e corruptas democracias africanas, com suas condições de vida desumanas, fomentam o desejo dos jovens a emigrar a uma terra mais promissora que seria a Europa.

N'dongo demonstra que a Europa é apenas um ponto dentro do circuito de migração, composto por passagens intermediárias e movimentos sazonais, tudo em constante fluxo. Não se trata somente de um deslocamento geográfico, mas sim, vistas pelo enquadramento social, são migrações a vários níveis (COSTA, 2011, p. 520). A identidade étnica de Lambert Obama começa a passar por uma transformação durante a sua trajetória e ele chega a questionar o sentido de sua viagem, antes de completá-la. Ele percebe o tamanho do esforço e os perigos que o esperam, assim como os sofrimentos que vai passar por estar longe da sua terra e dos seus entes queridos. Portanto, questiona a vigência dos seus objetivos para a fuga.

¿Merecía la pena arrostrar tantas penalidades por un futuro incierto? ¿Hubiera sido más conveniente seguir resistiendo en su país, presentando batalla a la diversidad, o perecer de una vez, quizá de una enfermedad penosa, de paludismo cerebral o algo así, o molido a palos por la policía, o sacrificado en un festín de brujos, o resignarse a la miseria, a su sino, a la existencia a la que había sido predestinado, pero consolado por el amor de los suyos y llorado por sus deudos? ¿Era éste el duro precio que debía pagar por intentar sustraerse al propio destino? (NDONGO, 2007, p. 291)

Obama viaja na condição de passageiro clandestino rumo à Espanha, porém é descoberto e desembarcado forçosamente em Dakar, onde ele já tem a primeira experiência de um emigrante ilegal. Contudo, após muitas dificuldades, consegue sustentar-se com a força do seu trabalho. A esperança de poder chegar na Europa o mantém ativo na luta diária pela sobrevivência. Depois de ter permanecido trabalhando durante 15 meses na capital do Senegal, ele consegue reunir dinheiro suficiente para continuar a sua migração. Compra uma passagem de avião para Casablanca, de onde consegue um transporte terrestre até El Aiune, no Saara Ocidental. Nessa cidade tem de aguardar a construção da patera, que levaria 35 pessoas até a ilha de Lanzarote nas Ilhas Canarias, das quais 16 falecem afogadas no trajeto em circunstâncias muito trágicas devido ao comportamento covarde e desumano do capitão do barco.

Todos esperaban que la patera se acercara más y les depositara en lugar menos expuesto, donde no les cubriera el agua. Pero la barcaza permanecía parada, mientras el patrón les obligaba a saltar, temeroso de ser descubierto y detenido por la Guardia Civil, la gendarmería española. Obama Ondo nunca sabría qué rápida maniobra realizó aquel hombre para volcar la canoa: sólo se encontró en el agua 
y empezando a nadar, mientras oía como en un eco el clamor de los pasajeros, los gritos desbocados de los desgraciados que se hundían, el chapoteo desesperado de los que no sabían nadar. A su lado se zambullía y emergía la cabeza de la mujer embarazada; instintivamente, la agarró por el cuello de su vestido la arrastró consigo hacia la playa (Ndongo, 2007, p. 346-347).

No romance de Donato N'Dongo, o barco é um cronotopo que indica uma trajetória ou fuga para um outro momento da vida. A relação entre tempo e lugar é indissolúvel e encontra a sua representação artística na literatura, segundo a definição de Bakhtin (KONÉ, 2015, p. 38). O cronotopo do barco está vinculado à história da escravatura e ao comércio com escravos negros pelo Oceano Atlântico, o conhecido comércio triangular entre África, América e Europa que durou mais de três séculos. O próprio Lambert Obama tem essa consciência quando compara a sua situação com os infelizes escravos nos navios negreiros (KONÉ, 2015, p. 43). "No estaba encadenado de pies y de manos, pero experimentaba las mismas sensaciones que los esclavos en aquellos barcos negreros de un tiempo anterior" (NDONGO, 2007, p. 291).

Também as personagens femininas chamam a atenção do leitor. O autor mostra, como na África as mulheres têm um papel submisso que não lhes permite desenvolver a sua personalidade, as impedindo de estudar e assumir uma profissão qualificada. Quando adultas, restam-lhes duas saídas: um casamento arranjado pela família com um homem adinheirado/endinheirado ou a prostituição. Ambas as situações levam as moças, em muitos casos, à infelicidade. Durante a curta vida de Lambert Obama, aparecem várias figuras femininas que o impactam e deixam o seu rastro. No início está a sua mãe Dorothée; que aparece como espírito protetor e reconfortante para Obama em seus momentos críticos durante a longa aventura (CELAYA, 2010, p. 146). A outra figura feminina importante é Anne Mengue, o seu primeiro e grande amor que aparece para engrandecer a figura de Lambert Obama. Depois da sua fuga, ele mantém uma relação breve com Danielle Eboué, uma mulher da camada social privilegiada que renuncia a ter amantes brancos e satisfaz os seus desejos com homens negros. Ela aparece como uma mulher manipuladora e insaciável, que faz Obama sentir-se um simples objeto (CELAYA, 2010, p. 148). Depois, ele estabelece uma relação estável com Sylvie em Douala. Ela chega a sustentá-lo através de atividades na economia submergida, uma situação que comove o jovem africano. Porém, são precisamente essas circunstâncias que o impulsionam a continuar com a sua migração em busca de melhores condições de vida para Sylvie e o filho deles. A situação descrita pelo narrador como a revolução da mulher africana resulta ao final insustentável para Lambert Obama, como para outros homens:

Dejaron de exigir dinero a sus maridos para ir al mercado, y los niños ya no se dirigían al padre, sino a la madre, cuando necesitaban un cuaderno. Asi se produjo una de las revoluciones silenciosas más determinantes de la reciente historia del continente: otrora altivos y dominantes, a los hombres se les bajaron los humos y, arrinconados y acomplejados, ya ni osaban perguntar de dónde salía el dinero que les permitía comer, y se limitaban a sentarse a la mesa em silencia reconcentrado y espeso (NDONGO, 2007, p. 257). 
Entretanto, não são somente homens que se submetem aos riscos da longa viagem para a Europa. Torna-se muito chocante observar que, em El metro, mulheres e mães encontram-se obrigadas a prostituir-se, sendo tratadas como se fossem apenas um "pedaço de carne", servindo somente para ganhar o dinheiro suficiente para poder empreender numa patera a travessia perigosa, e em muitos casos letal, entre a Saara marroquina até as Ilhas Canárias.

Vio a las tres muchachas, y actuaban como en una cadena de producción industrial: el cliente se acercaba, cogían el dinero, lo metían en un bolsito que les servía de almohada y se despatarraban sobre la estera; en cuanto despachaban al hombre encaramado sobre ellas, se levantaban, se levaban brevemente en la espuma del mar, se untaban el bajo vientre con una pomada lubrificante, cogían el dinero del siguiente y se tumbaban de nuevo. Obama Ondo reconoció a dos de ellas antes de que le tocara el turno: eran las gambianas que habían hecho con él el viaje en la furgoneta de Casablanca. Sólo después sintió el asco y le entraron los escrúpulos, por las maneras descarnadas, sin siquiera fingir un poquitín de ternura, todo tan prosaico, aquellos hombres vaciándose en ellas como las cabras en el poblado (NDONGO, 2007, p. 332).

Apesar da cena supramencionada, existe, na obra, um olhar próximo e repleto de afinidade para aquele "outro", o imigrante. O romance também relata as peripécias dos trabalhadores ilegais nas plantações e estufas do campo de Cartagena. Por ocasião de um acidente de trânsito, eles são demitidos e não recebem o salário que lhes corresponde. A falta de perspectiva, a ilegalidade e a persistência a alguns objetivos que o protagonista nunca alcançará, constituem os elementos frustrantes na vida de Obama, uma pessoa que, sobretudo, sonha com o regresso a sua terra natal. O livro retrata, ademais, certos preconceitos sob a perspectiva do "outro" nas duas direções: do branco sobre o negro e do negro sobre o branco, apesar de conter em sua narrativa momentos bonitos e conciliadores. A ação da narrativa volta, no final, ao lugar de início que é o Metrô de Madri, onde o jovem imigrante africano ganhava o seu sustento de cada dia vendendo bugigangas. Ele sofre um ataque fatal de neonazistas que descarregam nele todo o seu ódio racial com extrema violência (NDONGO, 2007, p. 456 ). ${ }^{20}$ Nesse momento, se revela a estrutura circular do romance, já que começou com uma recompilação das lembranças de Obama no mesmo lugar, no início do romance (RIZO, 2008, p. 88).

Apesar do tom pessimista, o livro contém alguns raios de esperança e de uma verdadeira solidariedade, não somente entre os migrantes africanos, mas também por parte dos espanhóis que trabalham em ONG's e se preocupam com a boa acolhida dos refugiados. Em vários momentos, o livro tem, de certa forma, o caráter de um manifesto que reivindica uma solução para os negros da África, soluções que lhes permitam continuar vivendo em seus países de origem com dignidade e bem-estar social. Através dos pensamentos de Lambert Obama, se articulam essas reivindicações, novamente estabelecendo uma relação com

20 Casos famosos e trágicos de crimes contra imigrantes na Espanha foram o assassinato da imigrante dominicana Lucrecia Pérez Matos, em 1992, em Madri e os linchamentos racistas em El Ejido (Almeria), nos dias 5-7 de fevereiro de 2000. 
a libertação da escravatura no século XIX:

Puesto que los negros no estaban predeterminados genéticamente para vivir en la miseria y en la opresión, no era mera fantasía soñar que podían transitar por mejores carreteras, gozar de viviendas dignas, circular en cómodos medios de transporte. Sólo se necesitaba voluntad, solidaridad, generosidad, perder el miedo a todo. Establecer un compromiso colectivo de reconquistar la libertad y el bienestar, del mismo modo que una generación anterior había conseguido recuperar la soberanía. (NDONGO, 2007, p. 447-448).

Certamente, trata-se aqui de um livro que induz à reflexão sobre as origens do problema da migração africana para a Europa, sobre costumes e tradições ancestrais e, sobretudo, sobre as condições econômicas e políticas reinantes na África subsaariana. A lição que aprendemos através da leitura desse texto amargo e provocador é: ninguém abandona o seu país e os seus entes queridos apenas por um capricho, mas somente por extrema necessidade para fugir de injustiças, perseguições, opressões, discriminações e pela falta de oportunidade de viver em condições dignas de um ser humano.

\subsection{LUIS GARCÍA MONTERO: NO ME CUENTES TU VIDA (2012)}

O poeta e atual diretor do Instituto Cervantes, Luis García Montero, publicou um romance de autoficção ambientado na Espanha contemporânea. Trata-se de uma obra literária complexa e multifacetada sobre migrações e exílios, memória histórica, identidade e conflitos entre gerações. O narrador em primeira pessoa fala ao seu filho Ramón sobre a sua vida; a vida de um escritor e professor de literatura que escreve um livro sobre um famoso poeta da geração dos 27, Pedro Alfonso, alter ego de Rafael Alberti, enquanto descobre a relação entre o seu filho Ramón e Mariana, a empregada romena de sua casa.

Ramón vai conhecendo a vida dos imigrantes romenos e latino-americanos em Alcalá de Henares e a tragédia dos imigrantes africanos que chegam em pequenas embarcações ou morrem afogados no mar. Estas experiências levam-no a questionar seu pai sobre a sua posição política, olhando sempre para o passado da Guerra Civil Espanhola. Ramon, seu pai Juan (o eu-narrador) e sua avó Ana representam três gerações diferentes de espanhóis; a geração jovem de hoje, aquela que liderou a transição à democracia e a do exílio. Tanto a discriminação social dos imigrantes como a sua perda de identidade são tópicos do romance, assim como a opressão sofrida por uma ditadura. A comparação entre a Espanha de Franco e a Romênia de Ceaușescu conduz a sérias reflexões sobre o passado histórico e o papel dos exilados espanhóis. Em outros textos literários contemporâneos, os imigrantes são relegados para posições subalternas como empregadas domésticas ou motoristas. Porém neste romance, o leitor acompanha a possibilidade de ascensão social e de transformação de suas vidas.

A narração começa com a visita de Ramón a Alcalá de Henares, onde mora Mariana. Ele conhece o ambiente de seu entorno e os amigos e companheiros romenos com os quais 
ela convive. Ele entra em contato, pela primeira vez de uma forma mais direta, com imigrantes, com cidadãos estrangeiros que vivem à margem da sociedade espanhola que vivem com outros costumes e outras preocupações, que se preocupam com a questão do retorno ou não à pátria, com as condições de uma vida longe de entes familiares queridos e com a realização de sonhos e com a ascensão econômica e social no país anfitrião, na Espanha. A viagem de Ramón de Madri a Alcalá significa um mergulho num mundo diferente para ele, que provém de uma família burguesa acomodada com ideais de esquerda.

Sabía que hay inmigrantes que llegan de África para sacar la cabeza y respirar fuera del agua podrida de la miseria , inmigrantes como los bolivianos o los marroquíes que esperan ahorrar dinero con intención de volver a sus casas, e inmigrantes que quieren instalarse en cualquier rincón de una precaria felicidad, una felicidad modesta, pero con buenos televisores, y con móviles, y con tarjetas de crédito, y con cualquier gran superficie que pueda sustituir con sus ofertas a los grandes prados de las utopías o a los bosques umbrosos de los países injustos (GARCÍA MONTERO, 2012, p. 29).

Aos dois jovens namorados (mais a Mariana que a Ramón) lhes preocupa a reação dos pais quando descobrirem o relacionamento do filho com a empregada da casa. $\mathrm{O}$ fato de Mariana morar na rua Andrés Saborit faz ele investigar sobre esse personagem, descobrindo que era um político espanhol nascido em Alcalá de Henares, tipógrafo, jornalista e liderança sindicalista que passou de 1939 a 1977 no exílio. Na parte do romance chamada Cuaderno Negro, Juan conta a sua versão da vida ao filho que não quer ouvi-lo. Trata-se de um desabafo de um pai que não encontra as palavras e os momentos certos para conversar com o filho sobre questões essenciais da vida porque ele, o escritor e intelectual, está imerso na escrita do seu livro sobre o poeta. O conflito familiar chega à tona durante o tempo de veraneio na casa em Rota: a estranha convivência com a empregada e futura nora deixa o ambiente tenso e estoura quando o filho Ramón testemunha a tragédia da chegada de imigrantes africanos no litoral gaditano com terríveis consequências.

Entró por la puerta del patio mientras Lola y Juan desayunaban. Mariana estaba sentada con ellos. Se os han pegado las sabanas?, preguntó antes de desahogarse. Una patera, más de treinta cadáveres flotando en la bahía de Cádiz, nuestra bahía. No sé, tal vez haya algún superviviente, pero mejor que se quede escondido, no vayamos a acabar de matarlo. Esa es la historia, esa es la verdadera tragedia de hoy, la inmigración, las pateras, el hambre, la miseria real, y no los viejos cuentos de la guerra civil, ni los poemas de Pedro Alfonso, ni las memorias de os militares comunistas. Las víctimas de hace setenta años os importan más que las de hoy, claro, como no son republicanos españoles que les den por el culo. ¡Viva el nacionalismo del dolor! Aquí hasta las desgracias deben ser nacionales. ¡Qué tragedia, ay nuestro pasado injusto y triste! ¡Qué tragedia de hace más de setenta años! Ya está bien de guerra civil, papá, date un paseo por la playa y verás a los muertos de hoy, tapaditos con una manta (GARCÍA MONTERO, 2012, p. 191-192). 
Na narração também aparecem os emigrantes latino-americanos residentes em Alcalá de Henares, aqueles bolivianos, colombianos, equatorianos, peruanos que encontramos nas lojas, nos bares, nos restaurantes, nos supermercados, as manicures que atendem os clientes nos serviços das cidades. Alguns deles se sentem espanhóis e estrangeiros ao mesmo tempo, a língua e a origem cultural são os mesmos, porém sabem que são cidadãos de segunda classe. Um exemplo é Gabriel, o filho de um casal de imigrantes italianos, a quem todos chamam de Iniesta por sua paixão pelo jogador e pela seleção espanhola, que na época tinha conquistado recentemente a Eurocopa e a Copa Mundial de Futebol, fatos que fizeram Gabriel vestir, sempre com muito orgulho, a camisa vermelha da seleção. Nesse episódio do romance, entra a questão de identidade dos imigrantes, daqueles nascidos na Espanha e daqueles que chegaram da América Latina.

Gabriel Navas, Iniesta, el número 6 de la selección, era español, había nacido en Móstoles. Carmen y Ataúlfo eran bolivianos sin nacionalidad española, pero con permiso legal de residencia desde la regulación del año 2006. Casi ochocientos mil inmigrantes pudieron regularizarse con muchas facilidades [...] Pero las cosas volvían a estar muy difíciles por culpa de la crisis y de las leyes de extranjería. El tío Evaristo había entrado en España con un permiso de tres meses de estancia, una carta de invitación tramitada por su hermano Ataúlfo y dos mil euros. Era un viaje de tanteo, ganas de ver la familia y comprobar si podía quedarse. Ahora estaba sin papeles. Para legalizar la residencia hacía falta un permiso de trabajo, y para conseguir el permiso de trabajo necesitaba la residencia. Una pesadilla que se mordía en la cola (GARCÍA MONTERO, 2012, p. 263).

O romance de Luis García Montero estabelece algo como uma hierarquia entre os imigrantes, já que aparecem migrantes da Europa Ocidental, da Romênia, os latino-americanos, os africanos e os ciganos romenos, estes últimos no ponto mais baixo da escala, aqueles que vivem ainda em chabolas, favelas muito similares àquelas descritas por Luis Martín Santos no seu famoso romance Tiempo de silencio, publicado em 1962, que retrata uma Madri de miséria, fome e imundície do ano de 1949. Essa comparação implícita faz o leitor refletir sobre os avanços da sociedade espanhola e sobre a marginalização de imigrantes.

O narrador chega a visitar uma das favelas, onde moram os ciganos entre a via do trem de alta velocidade (AVE) e a autopista a Valencia. Ele pretende escrever um artigo para um jornal, ou seja, uma reportagem para fornecer uma imagem mais equilibrada que inclua as condições sub-humanas das moradias e que não fale somente de roubo e delinquência. No momento da sua chegada, Juan se lembra de um poema de Pedro Alfonso do ano de 1933 que descreve a extrema miséria no campo.

Tal vez entonces, ochenta años atrás, fuese posible descubrir una miseria semejante. O quizás en los primeros años de posguerra, en las secuelas más duras de la guerra civil. Pero aquellos miserables estaban en su país, en su pobreza, en su injusticia, enganchados a su propio destino, humillados por sus caciques, consolados o castigados por sus curas, perseguidos por la crueldad de sus explotadores. 
Los habitantes de El Gallinero, unas seiscientas personas, unos setenta bebés, uno trescientos niños, unas cien familias de gitanos procedentes de Rumanía, soportaban el vertedero de una existencia sórdida, fuera de su lugar, de cualquier lugar, como si los cuerpos humanos pudiesen respirar en el vacío, en un casco vacío, en una lata de cerveza aplastada, en un trozo de neumático, en la ceniza de una hoguera apagada (GARCÍA MONTERO, 2012, p. 394-395).

Os ciganos romenos se localizam no final da escala social, uma vez que eles são excluídos tanto pelos espanhóis como pelos próprios romenos que vivem em situação melhor com emprego e moradia em condições razoáveis. O romance levanta várias questões que poderiam incomodar o leitor espanhol: a contínua discussão sobre memória histórica da guerra e da ditadura nos faz esquecer os pobres e marginalizados que estão ao nosso lado ou que tentam entrar no nosso país arriscando a vida na travessia pelo mar?

A comparação da ditadura do general Franco com a Ceaușescu na Romênia também pode incomodar a parte dos intelectuais espanhóis que heroicizavam a resistência comunista contra o franquismo, incentivada por uma "rádio pirenaica" que tinha a sua sede em Bukarest e apenas queria insinuar aos ouvintes a proximidade ao território espanhol. O livro de García Montero levanta, ao mesmo tempo, diversas questões que possam inquietar o leitor numa narração que possui todas as características de uma autoficção, na qual o desentendimento entre as diferentes gerações é visível.

\subsection{ALGUMAS CONSIDERAÇÕES SOBRE EXÍLIO E MIGRAÇÃO NA ESPANHA}

Na história da Espanha ocorreram diversas ondas migratórias para o exterior. Desde o descobrimento da América houve migrações massivas para o Novo Mundo por diversos motivos, sejam eles econômicos, políticos, religiosos ou sociais. No século XX, houve uma grande avalanche de refugiados que saiu em 1939 do país depois do fim da Segunda República e da Guerra Civil Espanhola perdida. Além do êxodo pela fronteira francesa, houve uma fuga em embarcações pelos portos mediterrâneos nos últimos dias da guerra. Especialmente o porto de Alicante se transformou num símbolo dessa fuga desesperada, já que mais de 15.000 pessoas ficaram nos cais de Alicante esperando pelos barcos que teriam de levar os refugiados para o exílio. Foram cenas dramáticas naqueles últimos dias do mês de março de 1939, dos quais temos conhecimento, principalmente, pela famosa novela de Max Aub: Campo de los almendros (1968). Não houve filmagens nem fotografias daquela tragédia, mas sim essa famosa reconstrução literária, seguida de várias outras posteriormente, como Enric Valor: Enllá d'Horitzo (1991), Rafael Torres: Los naufragos de Stanbrook (2004), Eduardo Guzmán: La muerte de la esperanza (2006) para só citar algumas (JAECKEL, 2016, p. 296-301).

Mais de 81 anos depois, observamos outro drama humano nos cais de um porto espanhol, porém, desta vez, trata-se de imigrantes africanos que tentam entrar no país fugindo de seus países de origem por causa das deploráveis condições de vida. Neste caso, temos registros fotográficos e filmográficos dos acontecimentos no porto de Arguineguín, no mu- 
nicípio de Mogán, sudoeste da Ilha de Gran Canaria. Na atualidade, testemunhamos no píer desse porto um drama de imigração africana e não de emigração europeia, um drama que foi abarcado nas duas novelas analisadas. No romance de Luis García Montero, a comparação da situação atual com a de 1939 não é somente implícita, mas condiciona o conflito pai/filho.

\section{CONSIDERAÇÕES FINAIS}

Na comparação da ficcionalização da temática das migrações nas literaturas alemã e espanhola podemos observar algumas diferenças essenciais. Na Alemanha, a literatura escrita por ou sobre estrangeiros migrantes tem uma longa tradição e inicia praticamente com a chegada dos Gastarbeiter' nos anos 60 do século XX. Na Espanha, por seu lado, país emissor de trabalhadores convidados até os anos de 1970, se começa a retratar na literatura a situação de imigrantes apenas a partir dos anos de 1990. Outra diferença constatada se refere à origem dos autores ou das personagens dos romances. Na Alemanha, temos uma forte presença de escritores de países do leste da Europa, como Turquia, Bálcãs e Oriente Médio. Já na Espanha, dominam autores de países hispano-americanos e alguns poucos escritores de origem africana. A migração africana, porém, está presente nas publicações de autores espanhóis como, p. e, Luis García Montero, que retratam a vida de migrantes procedentes da Romênia, Bulgária ou Polônia.

No cenário literário da Alemanha é possível encontrarmos autores muito bem-sucedidos que se originam de localidades do Leste Europeu ou de países árabes, como é o caso de Wladimir Kaminer, Rafik Schami e Feridun Zaimoglu, que conquistaram um público muito amplo de língua alemã e também em outros países através das traduções das suas obras. As pesquisas acadêmicas sobre as produções literárias desses e de outros tantos escritores que escrevem sobre migração possuem um espaço significativo no âmbito acadêmico ao redor do mundo. Existem diversos estudos sobre Wladimir Kaminer na área de germanística, tanto artigos quanto dissertações de mestrado como é o caso de Vladimir Vertlib und Wladimir Kaminer im Vergleich ("Vladimir Vertlib e Wladimir Kaminer em comparação"), de Hana Crhová e "As representações espaciais em Schönhauser Allee, de Wladimir Kaminer”, de Gabriela Gomes de Oliveira, dentre outras produções. O mesmo ocorre com Rafik Schami, cujo trabalho literário é constantemente mencionado em textos científicos como em Vertraute Fremde. Erzählen und Alterität bei Rafik Schami ("Estrangeiros de confiança. Narrativa e alteridade em Rafik Schami”), de Linda Maeding e Zum Konzept der Multikulturalität im Werk Rafik Schamis ("Sobre o conceito de multiculturalidade no trabalho de Rafik Shami”), de Iman Osman Khalil. Sobre a obra de Feridun Zaimoglu, foi publicada em 2020 uma dissertação pela Universidade de Ankara, na Turquia, intitulada Gesellschaftskritik im Romanwerk von Feridun Zaimoğlu ("A crítica social no romance de Feridun Zaimoğlu"), de Nurhanım Aydın, além de inúmeros artigos acadêmicos que abordam as temáticas de seus livros.

No caso da Espanha, conhecemos autores bem divulgados e exitosos procedentes de países latino-americanos como, por exemplo, Mario Vargas Llosa, que escreve na atuali- 
dade, e autores como José Donoso, Roberto Bolaño ou Juan Carlos Onetti, cuja produção literária se deu em um passado recente. Em contrapartida, autores de origem africana geralmente não conseguem conquistar um público grande no mercado literário. A conhecida autora marroquina-catalã Najat El Hachmi pode ser considerada uma exceção. Podemos também considerar sintomática a falta de estudos acadêmicos sobre a literatura de migrantes em espanhol e outras línguas oficiais da Espanha. Dois dos estudos mais completos sobre essa temática foram realizados por pesquisadores de universidades da Suíça (ANDRES-SUÁREZ; KUNZ; D’ORS, 2002) e da Croácia (ZOVKO, 2019).

Quais seriam as possíveis explicações para essas diferenças? A Espanha, com o seu longo passado colonial, tem uma postura mais aberta aos imigrantes do chamado Novo Mundo - algumas vezes similar a uma atitude paternalista e uma postura mais hostil frente aos imigrantes procedentes da África que chegam em massa a cada mês devido à proximidade geográfica do país. Pode parecer que a escrita mágica latino-americana é geralmente mais valorizada do que a crua realidade exposta por autores africanos, árabes ou por espanhóis que escrevem sobre imigração africana. Na Alemanha, devido a sua falta de uma história colonial expressiva, não existem essas preferências ou vínculos históricos. ${ }^{21} \mathrm{Na}$ Espanha podemos ainda constatar uma forte presença dos rastros do próprio exílio entre os elementos progressistas, somente em 2019 houve 80 eventos de bastante repercussão, comemorando o $80^{\circ}$ aniversário da saída forçada para o exílio republicano em 1939, enquanto a parte ultraconservadora considera os latino-americanos ainda hoje como "espanhóis nascidos em Bogotá, Buenos Aires, México". Ambas as visões enfocam na América Latina, como destino ou origem da migração, e negligenciam a problemática das migrações atuais procedentes de países africanos e árabes.

$\mathrm{Na}$ Alemanha, pelos motivos citados, não existe uma preferência específica por uma região geográfica e, apesar de que o anti-islamismo se manifeste abertamente nos últimos anos, autores de países muçulmanos conseguem conquistar um grande público leitor na Alemanha. Outra diferença significativa pode estar no fato de que muitos autores que escrevem ou que possuem um passado relacionado à migração, recorrem ao humor e à ironia como base de sua escrita literária. Essa postura acaba por, de certo modo, facilitar a recepção de suas obras diante do mercado de língua alemã. Sendo assim, esse fator parece diferenciar os autores migrantes pertencentes à literatura de língua alemã daqueles residentes na Espanha. Finalmente, pode-se constatar que o tema da migração ganhou muita força nos últimos anos nas duas literaturas, de modo que os romances e contos sobre as travessias recentes de refugiados por mar ou por terra estão ainda a ser escritos.

21 O império colonial da Alemanha durou pouco mais de trinta anos 1884-1918, tinha uma grande extensão geográfica, porém pouco impacto sobre a economia alemã e a formação de uma consciência colonial no povo alemão. O massacre cometido por tropas coloniais entre as tribos Herero e Nama, 1904-1908, na atual Namíbia somente foi reconhecido pela Alemanha no século 21. 


\section{REFERÊNCIAS BIBLIOGRÁFICAS}

ABRIL, Juan Carlos. Reseña de Luis García Montero: No me cuentes tu vida. In: Castilla. Estudios de Literatura, n. 4, 2013, pp. 100-105.

ANDRES-SUÁREZ, Irene; KUNZ, Marco; D’ORS, Inés (eds.). La inmigración en la literatura española contemporánea. Madri: Editorial Verbum, 2002.

BUNDESAMT FÜR MIGRATION UND FLÜCHTLINGE. Asyl \& Flüchtlingsschutz. Em: https:// www.bamf.de/DE/Themen/AsylFluechtlingsschutz/asylfluechtlingsschutz-node.html Acesso em: 30 de novembro de 2020 .

BUNDESAMT FÜR MIGRATION UND FLÜCHTLINGE. SoKo-Analyse für das Halbjahr 2020. Em:<https://www.bamf.de/SharedDocs/Anlagen/DE/Forschung/BerichtsreihenMigrationIntegration/ SoKo-Analysen/soko-halbjahresbericht-2020.html?nn=281840> Acesso em: 30 de novembro de 2020.

CANDAN, Menderes. Die irakische Diaspora in Deutschland: Struktur, Organisation, Aktivitäten und entwicklungspolitisches Engagment. Düsseldorf: Deutsche Gesellschaft für Internationale Zusammenarbeit, 2017.

CELAYA, Beatriz. De vitorias o derrotas. El metro, de Donato Ndongo-Bidyogo. In. Romances Quarterly, n. 57, 2010, pp. 142-157.

COSTA, Cátia Miram. Donato Ndongo e o exílio literário. In: Crítica Cultural, v. 6, n. 2, 2011, pp. 503523.

HERRERA, Lilian Salinas. Desplazamientos: los imaginarios de la travesía de Jean en Ciudad Berraca y Obama de El metro. In: Revista Letras, São Paulo, v. 59, n.1, 2019, pp.97-113.

HISTÓRIA ISLÂMICA. Baathismo: Conheça a História do Socialismo Árabe. Em: <https:// historiaislamica.com.br/baathismo-conheca-a-historia-do-socialismo-arabe/> Acesso em: 30 de novembro de 2020 .

JAECKEL, Volker. A recuperação e a recriação literária da memória histórica do fim da Guerra Civil Espanhola em Alicante. In: Graciela Ravetti, Rômulo Monte Alto. (Orgs.). Literaturas modernas e contemporâneas: reflexões críticas entre Belo Horizonte e La Plata. Rio de Janeiro: Jaguatirica, 2016, p. 289-308.

KHIDER, Abbas. Ohrfeige. Munique: Hanser, 2016.

KONÉ, Ténon. El barco como cronotopo en El Metro de Donato Ndongo-Bidyogo. In: Perífrasis, vol. 6, n. 37, 2015, pp 37-51. 
KUNZ, Marco. La inmigración en la literatura española contemporánea: un panorama crítico. In: ANDRES-SUÁREZ, I.; KUNZ, M.; D’ORS, I. (eds.). La inmigración en la literatura española contemporánea. Madri: Editorial Verbum, 2002. p. 109-136.

MONTERO, Luis García. No me cuentes tu vida. Barcelona: Editorial Planeta, 2012.

NDONGO-Bidyogo, Donato. El metro. Barcelona: Ediciones El Cobre, 2007.

PHOTONG-WOLLMANN, Pimonmas. Literarische Integration in der Migrationsliteratur anhand der Beispiele von Franco Biondis Werken. 1996. 218f. Tese (Doutorado em Estudos Literários) Universidade Chiang Mai, Tailândia, 1996.

RIZO, E. G. Review of El Metro by Donato Ndongo. In: PALARA, v. 12, p. 84-89, 2008.

ZOVKO, Maja. Itinerarios narrativos de la inmigración actual en España. Barcelona: Universitàt Autonoma de Barcelona, 2019. 